\title{
The emergence of native multi-sided platforms and their influence on incumbents
}

\author{
Andreas Hein $^{1}$ (D) $\cdot$ Maximilian Schreieck ${ }^{1} \cdot$ Manuel Wiesche $^{1} \cdot$ Markus Böhm $^{1} \cdot$ Helmut Krcmar $^{1}$
}

Received: 30 March 2018 / Accepted: 25 April 2019/Published online: 10 May 2019

(C) The Author(s) 2019

\begin{abstract}
Multi-sided platforms (MSPs) are one of the dominant designs of the digital age. However, prior research focuses mainly on established MSPs, leaving little insight into their emergence. We use the literature on technological trajectories and technology diffusion to derive four propositions that increase our understanding on the emergence of MSPs. The propositions include the emergence of native MSPs based on the assimilation of technologies in technological trajectories; how uncertainty influences incumbents to not follow those trajectories; how native MSPs create new demand; and how this demand eventually triggers the transformation process of incumbents to transform toward an MSP provider. We conduct a multiple-case study in the context of mobility services with three native MSP companies along with an incumbent that is transforming toward an MSP provider. The resulting process model shows that MSPs follow a process of sense-making and bricolage to assemble a service-oriented architecture, contrary to the incumbent who adopts technologies according to its institutional logic to improve existing products and processes.
\end{abstract}

Keywords Multi-sided platforms $\cdot$ Technological trajectories $\cdot$ Servitization $\cdot$ Platform evolution $\cdot$ Mobility services $\cdot$ Mobility platform

JEL classifications $\mathrm{O} 32 \cdot \mathrm{O} 33 \cdot \mathrm{O} 39 \cdot \mathrm{O} 14$

This article is part of the Topical Collection on Research Advances in Multi-Sided Platforms

Responsible Editor: Nizar Abdelkafi

Andreas Hein

andreas.hein@in.tum.de

Maximilian Schreieck

maximilian.schreieck@in.tum.de

Manuel Wiesche

manuel.wiesche@in.tum.de

Markus Böhm

markus.boehm@in.tum.de

Helmut Krcmar

krcmar@in.tum.de

1 Technical University of Munich, Chair for Information Systems, Boltzmannstr. 3, 85748 Garching bei München, Germany

\section{Introduction}

Advances in information technology are moving at an everaccelerating pace and push innovations in various fields. New smartphone generations, Internet of things devices and increasingly powerful cloud computing applications are only three examples of technology pushing innovation (Bharadwaj et al. 2013). In contrast, consumers are pulling for new solutions that range from sustainability to contribute toward issues such as decreasing carbon dioxide emissions to new forms of mobility to cope with increasing urbanization (Kasman and Duman 2015). This interplay of technological advances and economic pull factors form technological trajectories or innovation paths (Dosi 1982).

Multi-sided platforms (MSPs) are built on technological advances such as smartphones, cloud computing and data analytics to facilitate the interactions between supply and demand (Hagiu and Wright 2015; Tiwana et al. 2010). ${ }^{1}$ Prominent

\footnotetext{
$\overline{1}$ In the remainder of this paper, we will use the words "MSP" and "platform" synonymously.
} 
examples are mobility service MSPs, such as Uber, BlaBlaCar and Flixbus, which have disrupted the transportation industry. Those platforms challenge incumbents by utilizing an ecosystem of users and complementors that provide complementary products or services. Instead of owning mobility resources such as cars and buses, the platforms integrate and orchestrate an ecosystem of different actors (Willing et al. 2017). In addition, the success of platforms such as Apple's App Store triggered new demand represented by the emerging app economy (Perez 2017), where users expect convenient and easy to use digital services. The resulting demand has caused the transformation of incumbent firms such as Google and Microsoft who also adopted the concept of an app store. Both examples illustrate that MSPs use technological advances to create new demand and that this demand can cause the transformation of incumbents to adopt an MSP model.

However, platform literature mainly focuses on mature platform ecosystems (de Reuver et al. 2017; McIntyre and Srinivasan 2017) and provides little insight into how MSPs emerge. It remains unclear as to which technological trajectories influenced the emergence of MSPs and how this emergence influences incumbent companies to adopt an MSP (Tiwana et al. 2010). Examining startups that natively adopted an MSP and grew to industry-leading platform companies could help to identify technological trajectories that influenced the emergence and further evolution of MSPs. Furthermore, empirical insights into the process that describes the emergence of MSPs and the influence of successful MSPs on established industries could help scholars and practitioners develop a better understanding of the phenomenon of MSPs. In total, this article answers the following research questions.

(1) How do technological trajectories foster the development of native MSPS?

(2) How do incumbents react to trajectories that fostered the development of native MSPs?

(3) How do native MSPs trigger the transformation of incumbents to transform toward an MSP provider?

To answer the research questions, we first derive four propositions according to the literature of technological trajectories and technology diffusion. The four propositions follow the phases of the emergence of native platform companies through risk-taking actors and the subsequent diffusion and internalization among incumbents in an oligopolistic market (Dosi 1982). We evaluate the four propositions based on an embedded multiple-case study (Yin 2017). The multiple-case study comprises the three native platform companies Uber, BlaBlaCar and Flixbus, and an incumbent that currently transforms toward an MSP provider. We use the context of mobility services as it reflects a contemporary phenomenon in that an increasing number of incumbents in the automotive industry shifted toward a service-oriented business (e.g., DriveNow owned by BMW, car2go owned by Daimler). Besides, there are concepts from automotive companies to establish an MSP that incorporates an ecosystem of mobility actors in the case of Toyota Mobility Services (IEEE Connected Vehicles 2016). By validating technology push and demand pull factors in a cross-case analysis, we derive a process model that explains how native MSPs emerged, how incumbent firms reacted to native MSPs in the first place and how the native platforms triggered the transition of the incumbent toward an MSP provider.

\section{Theoretical background}

During the past decades, scholars have relied on two dominant perspectives to explain the direction of technological change: technology push and demand pull (von Hippel 1976; Mowery and Rosenberg 1979; Rosenberg 1969; Schmookler 1966). Over time, researchers such as Dosi (1982) and Kline and Rosenberg (2010) have advocated a shift from a linear to a more interactive model of technological change. They use technological trajectories as a combination of technology push and demand pull to describe the direction of technological advances. In recent years, a combination of several trajectories has led to the genesis of digital convergence, fostering the development of new types of business models such as MSPs (Yoo et al. 2012).

\section{Technological trajectories}

Technology push proponents argue that basic science is the foundation for applied research that enables product development and commercial production of innovations (Nemet 2009; Rosenberg 1969; Nelson and Winter 1977). The central thesis is that advances in science determine the rate and direction of innovations (Nelson and Winter 1977). Those advances account for the increased role of scientific inputs in innovative processes and the emergence of disruptive technological advances (Freeman 2000; Dosi 1982). The "TRACES" project, sponsored by the National Science Foundation, revealed that 341 basic research events (e.g., in the field of magnetic ferrites or the video tape recorder) influenced future innovations in a time frame of 30 years (Isenson 1968). The downside of this lens is the risk of a "lab in the woods" approach, which views innovation in isolation of demand or the reinvention of the wheel through a lack of taking the market into account (Burgelman et al. 2008). In addition, the sole technology push perspective ignores pricing mechanisms, changing economic conditions and the process of growth and economic change (Dosi 1982; Costantini et al. 2015; Lee and Shim 2007).

On the contrary, advocates for the demand pull perspective argue that the market is the main actor when it comes to creating new business opportunities. Firms invest in 
innovations to satisfy unmet user needs, thus driving innovation (Schmookler 1966; Kleinknecht and Verspagen 1990). The fundamental argument of this research stream is that demand steers firms to work on unmet needs (Rosenberg 1969). The "Project Hindsight" provides support for this theory, where the U. S. Department of Defense presented that nearly $95 \%$ of all military innovations in the 1960s emerged from a particular defense need (Sherwin and Isenson 1967). Important demand-based factors are the price (Hicks 1963), the identification of current or urgent demands (Schmookler 1966) and potential new markets (Vernon 1966). The strength of this theoretical lens is to explain incremental innovation and to consider economic factors. However, the demand pull perspective fails to predict disruptive innovations that do not emerge from a market demand (Mowery and Rosenberg 1979), nor does the theory answer the when and why a technology emerges or develops (Dosi 1982; Nemet 2009; Costantini et al. 2015; Lee and Shim 2007).

Besides technology push and demand pull, there is a third factor of regulatory push. Empirical studies show that establishing or abolishing rules or regulations can lead to innovations (Jaffe and Stavins 1995; Porter and Van der Linde 1995). However, scientific research shows that regulatory push factors mainly influences eco-innovations triggered by environmental policies (Porter and Van der Linde 1995; Green et al. 1994; Rennings 2000). Besides technology push and demand pull, we decided to control for regulatory push factors due to the ecological sensitivity of mobility services regarding carbon dioxide reduction.

Out of this discussion, researchers found consensus on the shortcomings of each perspective and moved toward a common explanation for technological change (Dosi 1982; Mowery and Rosenberg 1979; Singh et al. 2015). Dosi (1982) used the notion of technological paradigms following Kuhn's scientific paradigms as a model and pattern of solutions for a selected technological problem (Dosi 1982; Kuhn 1996). Building on this, each technological problem can be solved in different ways through technological paradigms that manifest as a technological trajectory. The transition from labor-intensive work to mass production represents a shift in technological paradigms. Mass production uses different skills and heuristics to solve the problem of increasing production throughput. A technological trajectory or way to solve this problem based on the paradigm of mass production is mechanization in the form of the conveyer belt compared with the labor-based made-to-order paradigm. In this way, technological trajectories emphasize the interplay between technology push through the underlying technological paradigm and the demand pull through economic traction (Dosi 1982; Singh et al. 2015).

The innovation diffusion literature provides three steps on how organizations can assimilate with innovations or technological trajectories. First, firms initiate and evaluate the potential benefits of the technologies in a trajectory. Based on the evaluation, firms adopt the technologies of trajectories for value-creating activities. Finally, there is routinization, where firms assimilate to the trajectory and the underlying technologies as an integral part of their value-creating activities (Zhu et al. 2006; Rogers 2003). However, organizations have limited resources, which poses a challenge in their ability to assimilate any but the most promising technological trajectories. The assimilation of a new trajectory also includes the risk of not meeting the anticipated benefit. As a consequence, companies follow a selection process (initiation) and consider a variety of economic, institutional and social factors. Examples range from economic factors such as the marketability, potential profitability, cost-saving capabilities, and economies of scale to institutional factors such as the company structure to social factors such as technology acceptance (Dosi 1982; Rosenberg 1976).

Another factor to consider is the maturity of companies regarding the willingness to follow technological trajectories. Dosi (1982) described this aspect as the differentiation of two phases that reflect the emergence and maturity of industries. The first phase involves economic trial and error, which characterizes the implementation and commercial exploitation of technological trajectories through risk-taking actors. Those actors try to routinize technological trajectories in the search for new profit and market opportunities. If successful, the risktaking actors can enjoy temporary monopolies. In this phase, incumbents do not follow new trajectories due to uncertainty regarding the technical approach or "means," uncertainty regarding market focus or "ends," and uncertainty regarding timing or "urgency" (Pearson 1990). Scientific research suggests that technology push factors dominate the first phase (Pavitt 1984). In sum, the first phase describes the emergence of native platforms characterized by risk-taking actors that assimilate technologies in technology push-dominated trajectories (Dosi 1982; Pavitt 1984). Furthermore, uncertainties in the initiation process regarding the technical approach, market focus and timing prevent incumbents from assimilating technologies in the same trajectories (Pearson 1990; Dosi 1982). An example is the rise of Apple's iTunes as an MSP, where traditional vendors of CDs (incumbents) did not follow the new technological trajectory. Risk-taking actors are motivated by commercial success in high reward markets, while incumbents need to evaluate new technologies in the light of economic, institutional and social factors (Dosi 1982; Rosenberg 1976). This behavior is closely linked to the Innovator's Dilemma (Christensen 2016). For the context of MSPs, we therefore posit the following propositions:

Proposition 1

(P1): Risk-taking actors emerge as native MSP companies through the assimilation of technologies in technology push-dominated trajectories. 
Proposition 2

(P2): Uncertainties in the initiation process prevent incumbents from assimilating technologies in technology push-dominated trajectories to transform toward an MSP provider.

The second phase corresponds to an oligopolistic maturity where successfully routinized technologies in technological trajectories cause new demand. These new demand pull factors influence the assimilation process of incumbents by reducing the uncertainty toward technologies in the technological trajectory, which in turn leads to diffusion and internalization among incumbents (Dosi 1982; Rogers 2003; Zhu et al. 2006). Hence, the second phase can be split into one phase that characterize the routinization of technologies in technological trajectories to create new demand and a third phase that describes the diffusion and internalization among incumbents. Particularly relevant for the second phase are demand pull factors that foster the further diffusion of technological trajectories (Pavitt 1984). Based on the mitigation of uncertainties, incumbents follow the new demand pull-dominated trajectory in the third phase by assimilating technologies (Dosi 1982; Pavitt 1984) with the goal to transform toward a platform. For the context of MSPs, we propose:

\section{Proposition 3}

(P3): Native MSP companies that routinize technologies in technology push-dominated trajectories create new demand pull-dominated trajectories.

Proposition 4

(P4): Incumbents become aware of the new demand pulldominated trajectories and assimilate technologies used by native MSPS to transform toward an MSP provider.

\section{Evolutionary dynamics of platforms}

The current state of research is that the convergence of technological trajectories in the form of media content, data storage and data distribution has led to the emergence of technologyenabled MSP companies such as Spotify and Hulu (Yoo et al. 2012). Further examinations emphasize that technological platforms have emerged as a new concept, resilient to the fast pace of changing technological trajectories (Tiwana et al. 2010). The platform ensures stability through a modular architecture that can be extended with new technologies, referred to as stable flexibility (Kim and Kogut 1996; Sanchez and Mahoney 1996). The platform achieves this stable flexibility regarding changing market condition in two ways. First, the MSP follows a design of interconnected modules that are connected via standardized interfaces. The standardization fosters network effects between modules as each module communicates with the next without further translation costs (Katz and
Shapiro 1994). This effect is also referred to Metcalfe's law (Metcalfe 2013). Second, the platform ensures composability, which refers to the resistance of modules to change (Tiwana et al. 2010). The platform can adopt new market trends by exchanging or enhancing modules without compromising the whole system. As a result, the platform enables malleability, which refers to the adoption of evolving user needs by enabling a flexible reconfiguration or extension of existing modules (Messerschmitt and Szyperski 2005). Through a modular platform, the platform owner can distribute new technologies to an ecosystem of users and complementors through software development kits (Ghazawneh and Henfridsson 2013). Thus, the platform enables knowledge diffusion among complementors, which in turn fosters the development of complementary innovations. One example is the introduction of Apple's ARKit, which enabled complementors to take advantage of the new Augmented Reality functionality to create new applications. Each new complementary innovation increases the value of the platform through network effects (Tiwana et al. 2010; Kim and Kogut 1996).

\section{Research design}

The research design follows a multiple-case study (Eisenhardt 1989) of three native platforms and an incumbent in the field of mobility services (Hein et al. 2018b). For the three native platforms, we draw on an embedded multiple-case study (Yin 2017) to describe the influence of technology push and demand pull factors that led to the emergence of MSPs and their impact on an incumbent. In analogy to other research (Karhu et al. 2018; Wright and Zammuto 2013) and to mitigate a hindsight bias (Fischhoff and Beyth 1975), the embedded multiple-case study is built on four different archival data sources in alignment with the two phases stated in the propositions. Second, a singlecase study integrates the perspective of an incumbent that was transforming toward an MSP (Yin 2017). Semi-structured interviews reveal what factors prevented the incumbent from following the same technology push and demand pull factors that led to the initial emergence of native MSPs and what new factors eventually triggered the transformation. Finally, a cross-case analysis compares the case of the incumbent with the native platforms to conclude the applicability of the propositions in a process model (Eisenhardt 1989; Yin 2017).

\section{Native multi-sided platforms}

The embedded multiple-case study is subject to three native mobility service platforms to elaborate on the view of risktaking actors that leveraged technology push and demand pull factors. To reduce the influence of contextual factors such as different business models, we selected three well-established platform companies, ranging from the field of peer-to-peer 
ridesharing to intercity bus traveling to carpooling (see Table 1). All companies started with a platform model (native MSP) and managed to establish a vibrant ecosystem of complementors and users. We rely on archival data to mitigate the hindsight bias of native platforms where the evolution toward an MSP seems to be predetermined. Contrary to interviews, archival data only covers information about the past and present (Fischhoff and Beyth 1975) and does not provide any information on the future use of technological advances or market demand.

For the data gathering process, we collected market reports and technological forecasts in a period two years before the founding of the three native platforms to describe the emergence of native MSPs. Market reports reveal current trends and uncover demand pull factors, whereas technological forecasts, such as the Gartner Hype Cycle, help detect technology push factors. In addition, we gathered archival data and empirical research from the founding date to early 2018 to elaborate on the evolution of the three native MSPs and their impact on the incumbent. Each fact was cross-validated through data triangulation within and between the two periods (Klein and Myers 1999). Overall, we collected 35 market reports and technology forecasts, 18 sources of archival data and 35 empirical studies. We used this data to test the validity of propositions one, where risk-taking actors emerge as native MSPs by assimilating technologies in technology pushdominated trajectories and proposition three, where evolving native MSPs create demand pull-dominated trajectories.

\section{Incumbent that is transforming toward an MSP provider}

In the single-case study, we analyzed the case of an incumbent in the field of mobility services that was transforming toward an MSP provider. Regarding the sampling strategy, we focused on a non-platform mobility company that acted as an incumbent and was transitioning (early 2018) toward a platform. We used interview data to capture the qualitative aspects of organizational uncertainty (Patton 2014). Another aspect that speaks in favor of interviews is the fact that the incumbent was transitioning toward a platform, which represented a contemporary event (Yin 2017). In addition, observing this phenomenon offered the opportunity to determine which technology push and market pull factors the incumbent adopted and which not. Furthermore, employees and decision-makers could justify their decision of not following the technological trajectories in the first place and instead elaborate on what factors eventually triggered the transformation process. Hence, we first determined factors that prevented the adoption of technology push and demand pull factors that led to the existence of native platforms. Second, we combined the interviews of the incumbent with the data of the native MSPs to reveal what factors eventually triggered the transformation process of the incumbent. We added market reports and technological forecasts over two years before the time when the transformation was triggered to make sure that we can determine if not-yet-identified demand pull or technology push factors influenced the transformation process. In total, we conducted ten face-to-face interviews between December 2017 and February 2018, each lasting 24-65 min (see Table 2). Besides, the interviews were recorded, transcribed, anonymized and sent back to the interviewees to provide additional comments. The final transcripts are the basis for further data analysis.

\section{Data analysis}

The data analysis follows the mechanisms of open, axial and selective coding as proposed by Strauss and Corbin (1990). We adhered to word-by-word open coding of the market reports, technological forecasts, archival data, empirical research and interviews to derive information such as technology push, demand pull factors and uncertainties of the incumbent. In total, we coded 102 data sources with 184 different in-vivo codes.

During the process of axial coding, we used a narrative strategy to link each code with the temporal perspective of
Table 1 Case descriptions of native MSPs

\begin{tabular}{ll}
\hline $\begin{array}{l}\text { Native } \\
\text { MSPs }\end{array}$ & Case Description \\
\hline Uber & $\begin{array}{l}\text { Founded in 2009, Uber is a peer-to-peer ridesharing platform based in San Francisco, California. } \\
\text { The platform matches individual Uber drivers (supply) with passengers (demand) by providing } \\
\text { value-adding services such as matchmaking, payment and rating mechanisms. }\end{array}$ \\
BlaBlaCar & $\begin{array}{l}\text { Founded in 2006, BlaBlaCar is a carpooling platform based in Paris. The platform matches } \\
\text { regular commuters or casual drivers (supply) with passengers (demand) to travel together. The } \\
\text { platform provides value-adding services such as matchmaking, rating mechanisms and } \\
\text { integrated payment. }\end{array}$ \\
Flixbus & $\begin{array}{l}\text { Founded in 2011, Flixbus is an intercity bus service platform based in Munich. The platform } \\
\text { integrates a variety of independent bus companies (supply) and matches them with mid-, to } \\
\text { long-range drivers (demand). The platform provides value-adding services such as } \\
\text { matchmaking, routing, rating mechanisms and integrated payment. }\end{array}$ \\
\hline
\end{tabular}


Table 2 Case description and interviewees of the incumbent in the mobility industry that is $t$ transforming toward an MSP

\begin{tabular}{|c|c|c|c|}
\hline Case Description & \multicolumn{2}{|c|}{ Interviews (Role of interviewee) } & \multirow{2}{*}{$\frac{\text { Duration }}{46: 51 \mathrm{~min}}$} \\
\hline \multirow{10}{*}{$\begin{array}{l}\text { Alpha is one of the market leaders regarding infrastructure } \\
\text { and mobility services around the world. The company } \\
\text { has long-standing IT know-how and transportation expertise. } \\
\text { Their core business is offering mobile solutions in the field } \\
\text { of logistics, smart cities and infrastructure. The company } \\
\text { is currently moving toward a smart mobility platform and } \\
\text { trying to engage an ecosystem of actors to co-create value. }\end{array}$} & 1 & Principal Smart Embedded System Key Expert & \\
\hline & 2 & Product Manager & $61: 13 \mathrm{~min}$ \\
\hline & 3 & Program Manager & $40: 00 \mathrm{~min}$ \\
\hline & 4 & Principal Cyber-Physical System Key Expert & $38: 08 \mathrm{~min}$ \\
\hline & 5 & Digital Solution Manager & $52: 31 \mathrm{~min}$ \\
\hline & 6 & Chief Expert Software & $36: 54 \mathrm{~min}$ \\
\hline & 7 & Head of IT & $62: 13 \mathrm{~min}$ \\
\hline & 8 & Head of Sales & $35: 14 \mathrm{~min}$ \\
\hline & 9 & General Manager (Head of Mobility Services) & $26: 45 \mathrm{~min}$ \\
\hline & 10 & Program Manager Autonomous Driving & 23:59 min \\
\hline
\end{tabular}

the data collection process (see Fig. 1) (Langley 1999). Hence, each code referred to one of the three phases that explains the genesis and diffusion of MSPs on the basis of technological trajectories. To describe why risk-taking actors emerged as native platforms, we compared the factors identified in the period two years before the founding of native MSPs with the initial offering of native platforms derived by archival data and empirical research. This comparison ensured that we only coded factors as relevant for the emergence of native platforms when those factors were also incorporated in the initial offering of native platforms. To further support this relationship, we also triangulated the data with statements from industry experts from the case company. Based on those findings, the interviews were designed to ascertain how the incumbent dealt with those factors in the assimilation phase of initiation and what factors (e.g., uncertainties) might have mitigated the decision to adopt an MSP in the first place. Factors identified within archival data and empirical studies in combination with interviews of the incumbent were used to derive new trajectories triggered by native platforms that were routinizing new technologies. Lastly, interview data were used to elaborate on factors that eventually triggered the incumbent's transformation toward an MSP provider. To make sure that not-yet-identified factors might have influenced the transformation process, we also use contemporary market reports and technological forecasts two years before the transformation for cross-validation. Finally, selective coding was used to test the validity of the four propositions across all cases. The result is a process model based on three temporal phases (Langley 1999) that describes the emergence of MSPs based on the assimilation process to technologies in technological trajectories (Eisenhardt 1989).

\section{Results}

The results describe the empirical data of the embedded multiplecase study subject to the three native platform companies and the subsequent single-case study of an incumbent transforming toward a platform. We use the three phases of $(I)$ emergence of native mobility service platforms ( $P 1$ and $P 2)$, (II) their influence on incumbents $(P 3)$ and the eventual (III) transformation of incumbents toward a platform $(P 4)$ to structure the data.

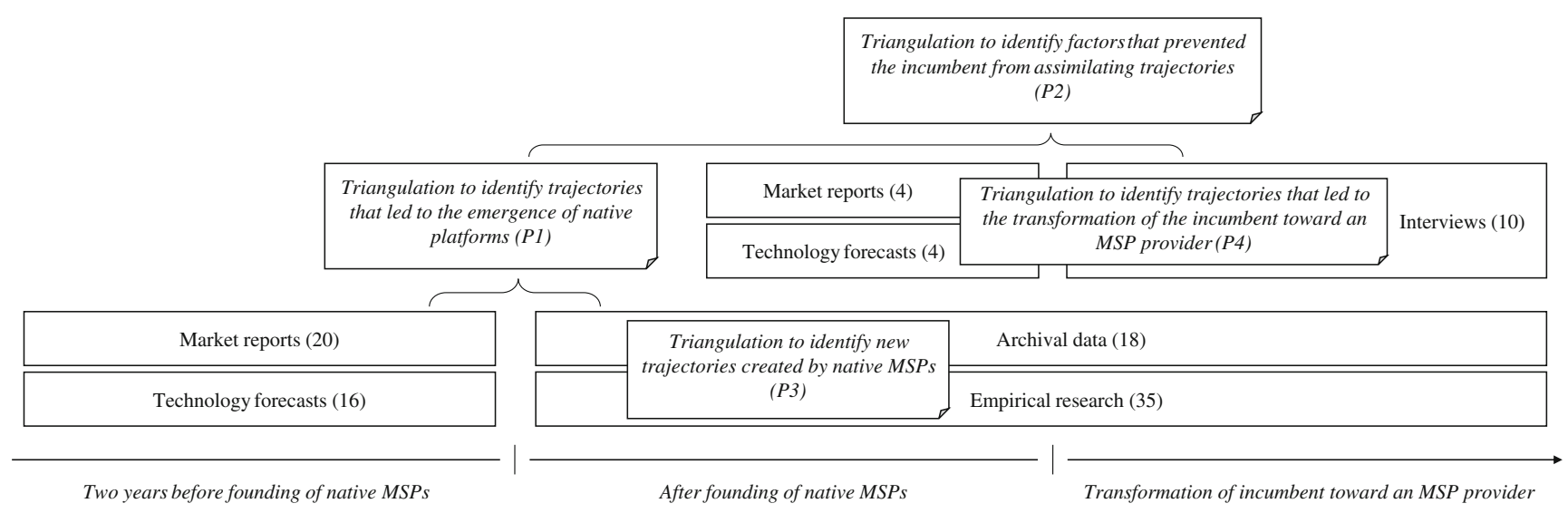

Fig. 1 Research model and theoretical propositions 


\section{Phase I: Emergence of native platforms}

The data from the market and technology reports and interviews indicate that there were four dominant technology push, three demand pull and one regulatory factor that led to the emergence of native platform companies. A factor is categorized as dominant if the factor was found in the market and technology reports and was also part of the initial native platform model (see Table 3).

\section{Technology push factors}

The first technology push factor represents Web 2.0 technologies such as AJAX or other client-side script languages that allow users to participate in or create own content. Prominent examples that utilize Web 2.0 technology are social networks (Macmanus 2006; Sutter 2009) or blogs (Butcher 2005; Fortt 2004). The Gartner Hype Cycle (2006-2009) indicates that Web 2.0 technologies started from the peak of inflated expectations in the year of 2006 and went from the trough of disillusionment to the slope of enlightenment (Gartner Inc. 2009; 2008; 2006). BlaBlaCar used this technology as the basis of their platform to enable users to share open seats on longdistance rides (Casprini et al. 2015). The concept of carpooling is not new. However, the use of Web 2.0 technology provided travelers with a central platform compared with the decentralized municipal sharing communities. The central platform enabled every user with internet access to offer and look for car-pooling opportunities on their personal computer (Rose and Wheeler 2017).

The second technology that affected the development of mobility service platforms is the mobile device or smartphone. The iPhone, which was introduced in 2007 by Apple, represented a quantum leap from regular cellular phones to smart devices. The smartphone provides convenient access to a variety of services in the form of applications (Sutter 2009; Forbes 2013). Technology trends (Fortt 2004) and the Product Manager of the case company "Alpha" confirmed that the smartphone and the underlying foundation, including the edge infrastructure, GPRs/3G technology and navigation software, were necessary for mobility service platforms to evolve. Uber emerged during the influence of this technology and used the smartphone from the very beginning to bundle navigation services with the ability to book limousines on the go (Kooti et al. 2017). Customers could determine their location and send it to the next driver, which in turn allowed them to track the exact location of the car. In addition, drivers were able to use Web 2.0 features to offer rides on the platform. Due to the rapid market penetration of smartphones, increasing numbers of users were able to access and participate (Web 2.0) in the Uber ecosystem (Sutter 2009).

The growth of mobility services precipitated a surge in demand for computational power to ensure reliable services, which brings the third technology push factor, cloud computing, into play. The Gartner Hype Cycle (2008-2013) indicates that the technology started as a technology trigger, peaked in 2009 to disillusionment, although it promised costeffectivity and a flexible increase of computational resources when needed (Gartner Inc. 2009; 2008; 2012; 2013). The Program Manager, Product Manager and Principal CyberPhysical Systems Expert of Alpha confirmed that cloud computing was a necessity for mobility service platforms to handle the continually growing amount of traffic and to lower marginal costs. Uber and BlaBlaCar went from a monolithic IT architecture to a platform that utilizes cloud services. While initially working with on premise hardware, both companies now use the Amazon Web Services (AWS) cloud computing platform to ensure the scalability of their services (Nappez et al. 2015; Kenney and Zysman 2016). Flixbus, on the other hand, adopted a combination of Salesforce and AWS cloud computing (Herrmann 2016).

The last technological factor is big data analytics, which offers companies the opportunity to take advantage of the increasing amount of data generated through Web 2.0 technology and mobile devices. Data analytics is the most recent technology and peaked in 2012 as a result of inflated

Table 3 Technology push and market pull factors during the initial founding of the platform (Phase I)

\begin{tabular}{|c|c|c|c|c|c|}
\hline \multicolumn{3}{|c|}{ Timespan (two years prior to founding year-founding year) } & \multirow{2}{*}{$\begin{array}{l}\text { ('04-'06) } \\
\text { BlaBlaCar }\end{array}$} & \multirow{2}{*}{$\begin{array}{l}\text { ('07-'09) } \\
\text { Uber }\end{array}$} & \multirow{2}{*}{$\begin{array}{l}\text { ('11-'13) } \\
\text { Flixbus }\end{array}$} \\
\hline Phase & Dimension & Factors & & & \\
\hline \multirow[t]{8}{*}{ Emergence of Native Platform Companies Phase I } & \multirow[t]{4}{*}{ Technology push } & Web 2.0 & + & + & + \\
\hline & & Mobile devices & o & + & + \\
\hline & & Cloud computing & o & o & + \\
\hline & & Big data analytics & o & o & + \\
\hline & \multirow[t]{3}{*}{ Demand pull } & Social media & o & + & + \\
\hline & & Affordable devices & + & + & o \\
\hline & & Sustainability & + & + & + \\
\hline & Regulatory & Liberalization & o & o & + \\
\hline
\end{tabular}


expectations in the Gartner Hype Cycle (Gartner Inc. 2012, 2013; Ulanoff 2012). Technological forecasts describe it as the next frontier of innovation (Manyika et al. 2011). Besides, the Principal Cyber-Physical Systems Expert of Alpha confirmed that the adoption of big data analytics technology is a logical consequence of the ever-increasing amount of data generated to increase the quality of the services offered on a continuous basis. Consequently, all three native platform companies use data analytics to take advantage of the generated data to increase the quality of their services (Nappez et al. 2015; Schlesiger 2016; Kenney and Zysman 2016).

\section{Demand pull factors}

The emergence of social media and digital word-of-mouth corresponds with the development of Web 2.0 functionalities (Macmanus 2006; Sutter 2009). All three native platforms were born into a world where social networks re-shaped the way we communicate, share and recommend products or services (Forbes 2013; Sutter 2009).

The second market demand is that newly developed mobile devices became increasingly affordable due to rapid market penetration. Cheap devices reinforce positive effects on reducing entrance barriers for potential service users (Sutter 2009). Thus, this trend has enabled an increasing number of users to benefit from the GPS sensor in their device in combination with the mobile Internet to calculate routes, book rides and consume services.

Lastly, there is the need for sustainability, where fuel is seen as the highest cost factor for commuting (Antich 2007) and car-sharing as a way to reduce carbon dioxide emissions (Cannon and Summers 2014).

\section{Regulatory factors}

Regulatory factors that triggered the emergence of mobility service platforms are adjustments to liberalize the public transportation industry. In the case of Flixbus, the Federal Republic of Germany repealed the monopoly of the Deutsche Bahn (German-based private transportation/ railway provider) on long-distance routes (Gremm 2017; Grimaldi et al. 2017). Besides liberalization, users adopt new services due to capacity issues with conventional modes of transportation. BlaBlaCar benefitted in this regard from a general strike of French railway companies, which forced people to seek alternative transport solutions (Rose and Wheeler 2017).

\section{Uncertainty}

The interview data gathered from the incumbent Alpha reveal ambiguity regarding the application of each technology on its own and hesitation to adopt a platform solution. Five interviewees indicated that the incumbent implemented each technology separately to support existing processes or to enhance the products. One example is the use of Web 2.0 functionality to gather feedback from clients, which is then used to improve existing products. Furthermore, Alpha used cloud solutions to reduce operating costs and introduced data analytics to improve their production processes.

In addition, the interviews reveal insights into why the incumbent did not follow an approach similar to the emerging native companies. First, the Head of IT of Alpha mentioned that data ownership was one of the most important topics when it comes to offering accurate and useful mobility services. Alpha did not see the opportunity to gather enough data to build a mobility service platform; the reasons for this range from regulatory or data privacy constraints to security standards. Furthermore, the Principal Cyber-Physical Systems Expert of Alpha stated that clients and ecosystem partners were reluctant to share their data. Second, Alpha struggled to find a solution for coopetition in their ecosystem. The Head of Mobility Services explained that Alpha is in direct competition with other mobility service providers; however, if they did plan to provide a platform solution offering valueadded services to their customers, then they would need to collaborate with competitors. During that period (Phase I), Alpha had no incentive to cooperate with competitors. While each of the possible ecosystem partners had different motives for participating in a platform ecosystem, Alpha was unable to provide a one-size-fits-all solution. Finally, Alpha did not have a compelling platform business case. The Head of Sales said that they had no pressure to be successful as they had a profitable business model and that startups were more eager to work hard to get their idea into reality. Furthermore, Alpha needed to justify the application of new technologies with a business case.

\section{Phase II: Impact of native platforms on incumbents}

The empirical results show that native mobile platforms triggered one technological advancement and three market-driven effects during the phase of routinization. As Table 4 indicates, the timespan for the routinization phase lasts from the founding year to the end of data collection (early 2018). Again, a factor was coded as relevant for this timespan if it could be cross-validated across archival data, empirical studies and interviews from industry experts represented by the case company Alpha.

\section{Technology push factor}

Native platforms combined technology push and demand pull factors as of Phase I to create a more robust infrastructure for handling the vastly increased amount of services (Rajesh 2016). Uber, for example, started with a monolithic 
Table 4 Technology push and market pull factors that result from the impact of mobility service platforms in the period after their founding (Phase II)

Timespan (founding year-end of study)

('09-'18) ('13-'18)

\begin{tabular}{llllll}
\hline Phase & Dimension & Factors & BlaBlaCar & Uber & Flixbus \\
\hline Impact of Native Platform Companies Phase II & Technology Push & Microservice architecture & + & & + \\
& Demand Pull & Servitization & + & + \\
& & Gig/Sharing economy & + & + \\
& & Coverage/Availability & + & + & + \\
\end{tabular}

architecture designed for single offerings in distinct cities and developed a microservice architecture capable of introducing and changing scalable services worldwide more quickly (Haddad 2015; Reinhold 2016). The architecture is based on cloud computing technology and aims to provide stability for the ever-increasing amount of service requests while also being flexible in adopting new services or changing existing services. Hence, the modular microservice architecture can manage the core value service (e.g., booking/offering rides) around supporting services that range from payment, authentication, rating rides and navigation. Besides, new services generated from complementors (Raasch et al. 2008) of the ecosystem can be integrated without disturbing the integrity of the architecture (Reinhold 2016; Fraud 2014). An example is the UberRide API, where developers can create valueadding services while the passengers are driving to their destination (Haddad 2015; Hein et al. 2018a).

\section{Demand pull factors}

Evolving mobility service platforms contribute toward servitization by distributing ride requests to a widely distributed network of drivers (Chen and Sheldon 2016; Posselt and Roth 2017). The driver can focus on the central mobility service as the platform takes care of secondary services that range from payment to navigation to matchmaking. So, mobility service platforms impact the way how we consume goods or services as no private car is needed to travel from A to B. Rapidly growing mobile services companies such as DriveNow or Car2Go are only two examples (Kooti et al. 2017). The Digital Solutions Manager of Alpha stated that a variety of other companies followed this trend as exemplified by carand bike-sharing: each focuses on a specific task or service and tries to map the service digitally. The Head of Sales summarized that service bundling is a crucial feature triggered by emerging platform companies. Native platforms led to people's expectation that the platform provides essential services such as ticketing, payment, reservation and peer-rating.

The second demand triggered by native platforms is the gig or sharing economy, which led to a shift from fixed contracts to a flexible work system. Uber drivers can decide when and how much they want to drive to earn a living (Chen and Sheldon 2016; Berger et al. 2018). Drivers have full control over their work schedule and can generate extra income when needed (Kooti et al. 2017). However, there are also critical voices pointing out that legislation has lagged behind the trend of gig companies. The case of Uber demonstrates that platforms operate in an underregulated market (e.g., the status of drivers regarding employment/insurance) (Drahokoupil and Fabo 2016).

Lastly, the flexible adoption of new subcontractors allowed native platforms to break new ground. Flixbus, for example, also covers less-frequented rural areas by connecting them through hubs in the form of big cities (Schlesiger 2016). Uber and BlaBlaCar follow the same pattern, where more people close to a destination using the service increase the value for all others nearby (Casprini et al. 2015).

\section{Phase III: Transformation of incumbents toward a platform}

Table 5 shows two dominant technology push and demand pull factors that influenced the incumbent's decision toward adopting an MSP. The interview results indicate that in addition to the factors of Phase II, blockchain technology (six independent mentions), artificial intelligence (nine independent mentions) and electrification (four independent mentions) influenced the incumbent's transitioning toward an MSP.

\section{Technology push factors}

The first additional technology push factor not triggered by the evolving platforms is the blockchain technology. The Program Manager of Alpha stated that this technology promises to establish trust and transparency in a mobility service ecosystem. Everyone can identify who altered which data or transaction and when. However, he also stated that the technology is at a too early stage to be applicable. Furthermore, the General Manager of Mobility Services pointed out that blockchain technology can help Alpha develop new business models where no intermediary or trusted party is needed to deal with contracts, 
Table 5 Technology push and market pull factors at the start of the transformation process of the incumbent (Phase III)

\begin{tabular}{lllll} 
Timespan (start of transformation-end of study) & & ('17-'18) \\
\hline Phase & Dimension & Factors & Incumbent (Alpha) \\
\hline Transformation of Incumbent Phase III & Technology push & Blockchain technology & + \\
& & Artificial intelligence & + \\
& Demand pull & Electrification & + \\
\hline
\end{tabular}

payments, or authentication. Blockchain and smart contracts manage all transactions to cope with the coopetition issue. Additionally, the Chief Expert of Software indicated that the blockchain could help mitigate data regulation problems by creating transparency and reducing the ecosystem complexity.

Artificial intelligence is the second technology mentioned to affect the transformation process. The Program Manager for Autonomous Driving indicates that artificial intelligence enables Alpha to provide users with a fully automated mobility service. The car can be sent just-in-time to the user's front door to offer them the best possible experience. Furthermore, Alpha can provide the service as cheaply as possible due to saving on personnel costs, in addition to being as reliable as possible due to the high degree of automation.

\section{Demand pull factor}

The additional demand pull factor deals with electrification, which Alpha recognizes as a trend toward e-mobility. According to the Principal Smart Embedded Systems, the demand promises a more ecological and less health-endangering technology that includes lower maintenance costs and easier integration in a connected car and with live updates. The demand drives the need for Alpha to come up with an architecture that supports the increasing number of smart/electrified devices.

\section{Discussion}

In alignment with the three phases and the four propositions, we discuss the implications, limitations and future research based on the empirical results (see Fig. 2).

The first phase characterizes the emergence of MSPs as an architecture of servitization. We use the notion of bricolage to explain that risk-taking actors adopt and assemble different technologies to support servitization, whereas incumbents adopt the technologies according to their institutional logic. While not being a central part of the adoption process, also regulatory factors can either enable (Flixbus and market liberalization) or amplify (BlablaCar and general strikes) the adoption process. Next, evolving native platforms cause new demand, for example, the gig/sharing economy and thereby establishing a trajectory toward mass servitization. During the initiation process, incumbents become aware of the new path but hesitate to follow it due to uncertainty. Eventually, native platforms routinize the assembled technologies as of Phase I as an architecture toward mass servitization. The resulting microservice architecture in combination with new
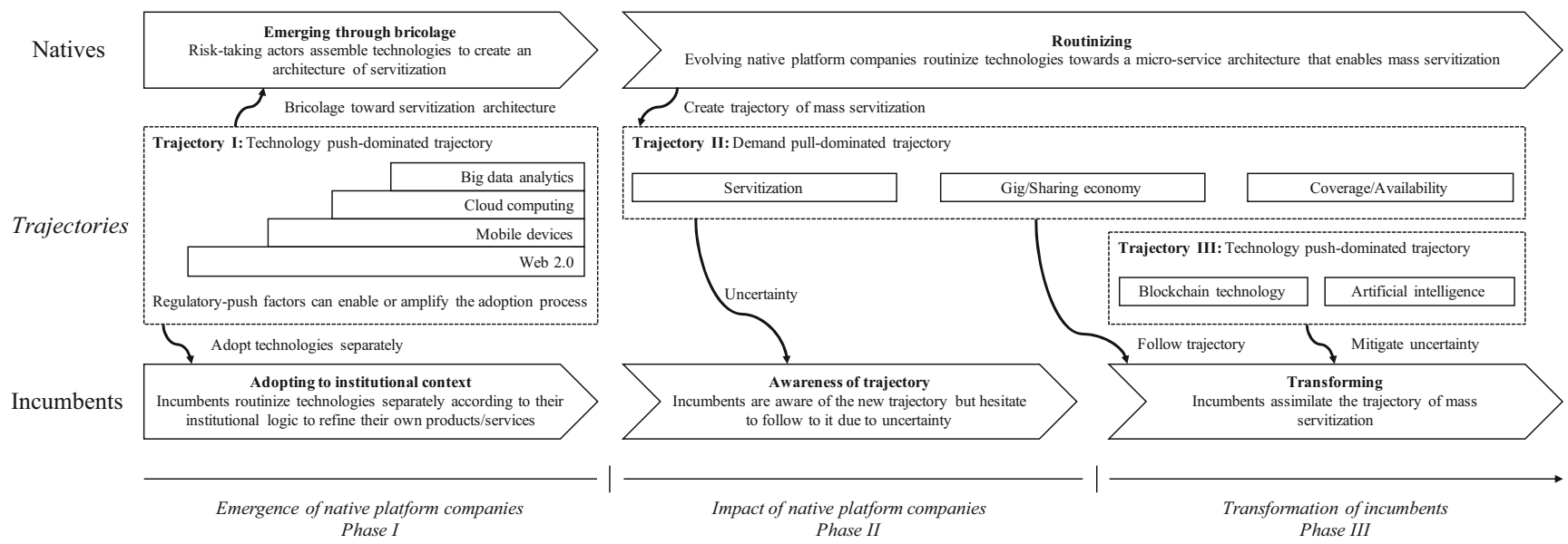

Fig. 2 Process model on the emergence of native platform companies and the transformation of incumbents toward an MSP provider 
technologies, such as blockchain or artificial intelligence, mitigates initial uncertainties and triggers the assimilation process of the incumbent.

\section{Bricolage: Assembling the architecture of mass Servitization}

Proposition 1 states that risk-taking actors emerge as platforms through the assimilation of technologies in technology push-dominated trajectories. However, the data indicate that those risk-taking actors do not assimilate to technologies in isolation but, instead, assemble them toward an architecture of servitization. We use the notion of bricolage to discuss the process of native platforms that assemble technologies and take advantage of market trends to develop an MSP based on an architecture of servitization (see Fig. 3).

Lévi-Strauss (1966) introduced the bricoleur as someone who has a limited number of tools and resources to perform many diverse tasks. In contrast to the engineer, who selects the tools and resources to achieve a planned goal, the bricoleur uses "whatever is at hand" (Baker and Nelson 2005). BlaBlaCar used the contemporary technology of Web 2.0 functionalities to solve the task of connecting a broad range of drivers with passengers. The original idea of Web 2.0 functionalities was to enable lively conversations and interactions on websites (O'Reilly 2007). Through sense-making, BlaBlaCar interpreted this concept in another way and enabled interactions between passengers and drivers by facilitating the offering of mobility services between the two groups.

Building on this basic level of interaction, mobile devices provided an increasing number of people with the opportunity to access mobility services regardless of their position. Uber took advantage of the GPS sensors in smartphones in combination with Web 2.0 functionalities. The result was a mobile application that provided drivers and passengers with convenient supporting services such as payment, tracking and peerrating to ensure trust.
Through the increased accessibility of mobility services, companies such as BlaBlaCar and Uber saw the need for improved performance, scalability and reliability of their service architecture. At the start, both companies built a monolithic architecture to support single services in isolated cities. However, as the cloud-computing technology became increasingly popular, the native platforms integrated this new technology to ensure the scalability of their mobile services (Alt et al. 2010).

Finally, the native platforms adopted the technology of big data analytics due to the vast amount of user- and devicegenerated data. All three mobility service platforms apply data analytics to improve their services continuously. Contemporary demand-based factors such as electronic word-of-mouth through social networks, a decrease in the costs of mobile devicesmaking them more accessible - and an increased awareness of sustainability further enhanced the composition of technologies.

The native platforms followed a process of sense-making of the different technologies according to their core mobility services and assembled them in the process of bricolage toward a microservice architecture. The microservice architecture is capable of splitting tasks into specific services. Those loosely coupled services act as modular entities connected through standardized protocols (e.g., in the form of an API). This architecture ensures composability due to the extensibility of services without compromising the whole architecture. Besides, the microservice architecture supports malleability due to the rapid adoption of new services and to the altering of existing services by dedicated service owners. Uber extends this concept not only to internal development but also to an ecosystem of external developers. The ride-sharing platform offers APIs such as UberRUSH or TripExperience. For the latter, Uber provides external developers with tools to create own services or applications for the time while the passenger gets to his/her destination (Hein et al. 2018a). According to Uber, the to-be-developed services aim to enhance the trip experience for the passenger (Saad 2016).

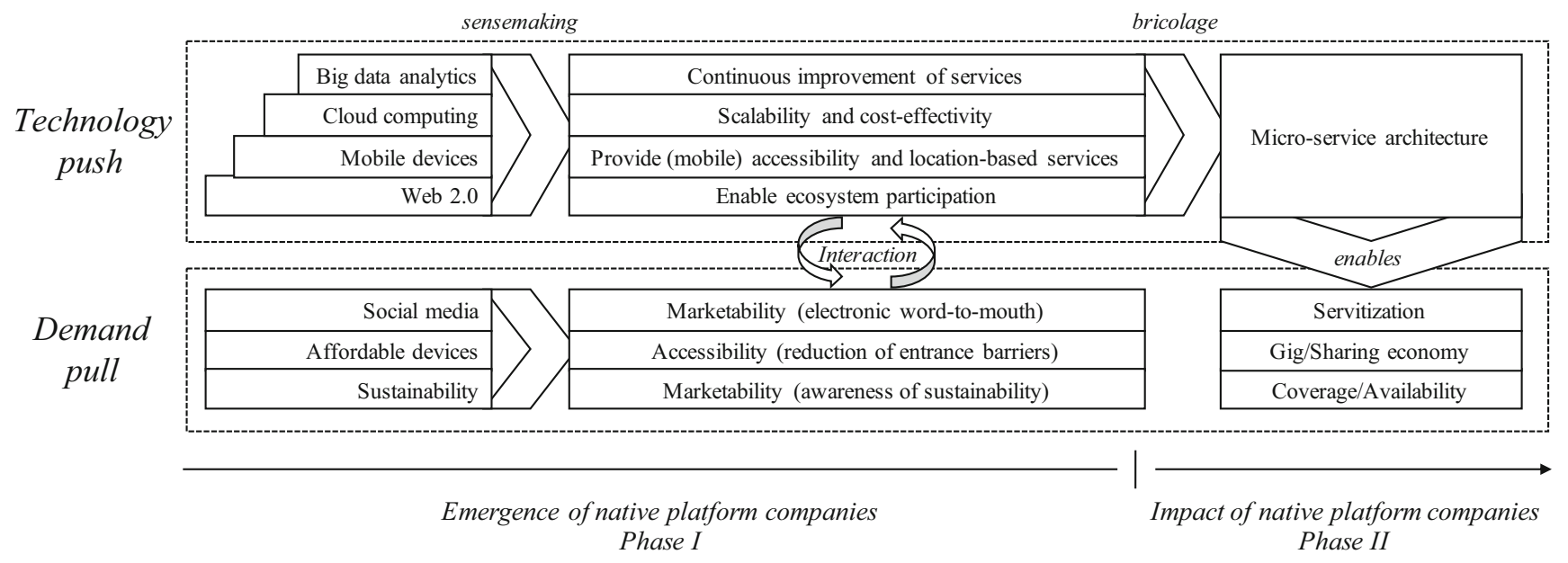

Fig. 3 Process of assembling technology push and demand pull factors toward an architecture of servitization 
Concluding, native platforms follow a process of sensemaking (Weick et al. 2005) of technology push and demand pull factors according to the provision of their core mobility services. In this context, the native platforms transitioned from a monolithic to a microservice-oriented architecture by tinkering with technologies to support their core service (Baker and Nelson 2005; Ciborra 2009). Reflecting on the initial proposition, we suggest that the assimilation process of technologies in technology-push dominated trajectories follows the concept of bricolage, where risk-taking actors assemble and tinker technologies to emerge as MSPs as an architecture of servitization.

Proposition 2 describes that incumbents hesitate to assimilate technologies in technology-push dominated trajectories due to uncertainty. As indicated in Fig. 2, our results show an ambivalent approach of incumbents. The interviews suggest that there are uncertainties that prevented the incumbent from adopting technologies such as unsettled data regulations, coopetition with ecosystem partners and a missing platform business model. However, those results are likely to incorporate a hindsight bias where the interviewees already knew about the platform and its role in the process of servitization. This bias becomes clear when observing the adoption of technologies separately. The incumbent indeed adopted each of the four technologies that led to the emergence of native platform companies according to its institutional logic (Thornton and Ocasio 2008; Alt and Klein 2011). They incorporated Web 2.0 functionality technically to gather customer feedback, used mobile devices to enhance the productivity of employees, or utilized cloud computing and big data analytics to improve manufacturing processes. Hence, the incumbent did not assemble the different technologies like native platforms did to support the provision of mobility services. In sum, it seems reasonable to conclude that it was less the uncertainty but more the lack of ambidexterity that could be the cause of an "Innovator's Dilemma" restricting the application of new technologies to the existing institutional logic to assemble an architecture of servitization (O'Reilly III and Tushman 2008; Christensen 2016).

\section{Creating demand: Prompting a trajectory toward mass Servitization}

During the impact of native platform companies in Phase II, the technology change literature proposes that native platform companies routinized technologies to create demand pulldominated trajectories (Proposition 3). The data support this proposition by illustrating that native platforms incrementally routinize the new technology stack as an architecture of servitization. Those native platforms create demand in the form of increased awareness of servitization, the transition from fixed to flexible employment represented by the gig or sharing economy and the coverage and availability of mobile services in rural areas. The awareness of servitization reflects the claim for convenience through service bundling where users see the platform as a one-stop shop. Users can plan trips, navigate possible routes, order from a pool of drivers and pay/ rate the service afterward without any media disruption. This kind of service bundling is an essential condition for user satisfaction (Ranganathan et al. 2006; Bouwman et al. 2007).

Furthermore, mobility service platforms led to the emancipation of service workers through increased flexibility. The term "gig" or "sharing economy" was shaped by Uber and describes that drivers are free to participate in the platform and accept passengers as they want. The driver can focus on the carriage of passengers as Uber takes care of additional services. This provision of services has influenced the emergence of an increasing number of mobility service companies such as bike- or car-sharing (e.g., car2go, DriveNow). However, the increased flexibility of drivers triggered the need for new regulations to mitigate the market power of platforms (Cannon and Summers 2014).

The steadily increasing adoption of mobility service platforms finally led to broad coverage of areas where the service is available. Flixbus started with highly frequented routes and then expanded into more rural regions around those hotspots. The satisfaction of those new demands was enabled by the microservice architecture, serving as a vehicle for the increased demand of servitization.

Eventually, the interplay of technological routinization and demand led to the development of MSPs as an architecture toward mass servitization. One can find a similar evolution when comparing the transition from made-to-order in the manufacturing industry to the technological paradigm of mass production. Architectures such as the assembly line and the conveyer belt helped reduce production costs and foster economies of scale through standardized tasks (Hounshell 1985). The emergence of native platform companies shows a similar pattern. While the move toward servitization is not new (Vandermerwe and Rada 1988), platforms reduce the transaction costs of the demand-side (passenger) and supply-side (driver) by providing them with an architecture of servitization that standardizes the interaction within an ecosystem (Hein et al. 2019).

Overall, the results validate that demand-dominated factors caused by the routinization of native platforms triggered the transition toward mass servitization through MSPs. As in the technology paradigm of mass production with dominant designs, such as the assembly line to the conveyer belt, the paradigm of mass servitization has also evolved from a monolithic architecture to a microservice architecture.

\section{State of liminality: Transition from the old to the new trajectory}

Proposition 4 suggested that incumbents eventually became aware of the demand pull-dominated trajectory and assimilated technologies used by native platforms, thereby mitigating 
the hesitation caused by uncertainty. We found evidence that uncertainty influenced the reluctance of assimilating the innovation path toward mass servitization as soon as the incumbent was aware of the new trajectory. First, interviewees within Alpha mentioned that mobility service platforms would not persist. However, during the evolution of native platform companies and the resulting demand, they found themselves in a state of liminality between the old and new trajectories, trying to make sense of this innovation path (Henfridsson and Yoo 2013). The Digital Solutions Manager of Alpha brings up the issue of not having a business case for a platform. This uncertainty illustrates that Alpha tries to assimilate to technologies in the trajectory toward mass servitization according to their current institutional logic, which is dominated by production processes and where they are unable to come up with a convincing business model. The same is true for the uncertainty regarding coopetition in Alpha's current ecosystem. Alpha would need to integrate competitors to provide a value-adding service. Alpha also found they were unable to cope with the data regulation laws to make the services work.

All three statements point toward issues that arise from applying a new trajectory to an obtuse institutional logic (Thornton and Ocasio 2008), where Alpha sees the need to transition from the old trajectory through a state of liminality to the new path toward mass servitization (Henfridsson and Yoo 2013). In this way, Alpha is currently looking for new technologies to help make sense of the innovation path coshaping new opportunities going along with the mitigation of uncertainties (Garud and Karnøe 2003). One promising candidate is blockchain technology, which could provide a business model for servitization, create transparency and trust in an ecosystem that includes competitors and allow users to see which data are stored. Concerning the initial proposition, we argue that assimilating technologies of a new trajectory is no binary decision caused by increased demand. Instead, demand triggers the assimilation process of technologies in the trajectory and leads to a transition from the current trajectory through liminality to the new trajectory (Henfridsson and Yoo 2013; Garud and Karnøe 2003).

\section{Implications, limitations and future research}

One of the fundamental research issues in the platform literature is that it is still unclear how platforms emerge (de Reuver et al. 2017). This article uses the theoretical lens of technological trajectories and technology diffusion to shed light on the early phases of platforms and their subsequent evolution. We show that native platform companies assemble different technologies such as ecosystem integration through Web 2.0 functionality, smartphones, cloud computing and big data analytics toward an architecture of servitization. The four different technologies converge in a new combination followed by a pattern of specialization (Kim and Kogut 1996), resulting in the microservice architecture.

First, we show that native platforms act as a bricoleur (LéviStrauss 1966), making sense of contemporary technologies to solve a mobility service-related problem effectively. Intuitively, native platforms "stumbled upon" a new architecture of servitization through bricolage (Garud and Karnøe 2003; Ciborra 2009). Out of this continually improving architecture, native platforms create new demand in the form of the gig or sharing economy. The combination of technological advances and an increased market need (Dosi 1982) leads to a new trajectory toward mass servitization. Within this innovation path, the platform facilitates supply and demand through a core service that is supplemented by several supporting services such as payment, matchmaking and peer-to-peer-based ratings. The increasing number of followers of incumbents in the form of DriveNow (BMW), Car2Go (Mercedes Benz) and Toyota Mobility Service (Toyota) indicates the importance of the innovation path. When taking the robustness of our findings into consideration, we see similar patterns when looking at other MSPs in the field of social networks and accommodation platforms such as Airbnb (Hein et al. 2018a). Those findings are in contrast to other research as shown in the example of Sun Microsystems diffusing the new paradigm of distributed computing (Garud et al. 2002). Instead of getting legitimacy through network interactions to diffuse the paradigm, native MSPs reinforce the trajectory toward mass servitization by creating new demand. This example of native platforms acting as bricoleurs to create novel, disrupting innovations can also be applied to other research areas. In particular, we shed light on the resource orchestration theory by exemplifying how native platforms bundle and routinize new technologies to pioneer an architecture of servitization (Sirmon et al. 2011).

Second, the process model contributes to the platform literature by revealing how native platforms assemble and routinize novel technologies to establish an MSP as an architecture that creates and satisfies the increasing demand for servitization. The study shows that native platforms first make sense of existing technologies from the provision of their core service, followed by the process of bricolage to come up with an infrastructure that supports the innovation path toward mass servitization. The routinization of this architecture led to new demand and a diffusion toward incumbent firms. Besides, the concept of the platform owner acting as a bricoleur may lead to further fruitful implications in the platform domains of platform governance mechanisms (Tiwana et al. 2010; Hein et al. 2016; Schreieck et al. 2018) and tinkering of platform openness through control (Boudreau 2010; Benlian et al. 2015). BlaBlaCar, for example, adjusted its booking service process to mitigate the problem of direct bargaining between the driver and the passenger and to increase service reliability. They started with a premium model that privileged paying drivers. However, the model proved to 
be unsuitable as this discriminated against most drivers. Next, they adopted a monthly plan model that failed due to the toosporadic character of facilitating commuting services. Ultimately, BlaBlaCar established a pay in advance service that creates the commitment to the ride and eliminated direct bargaining (BlaBlaCar 2018).

Third, we contribute to the technology and innovation management literature by showing that native MSPs act as bricoleurs to foster the exaptation of technologies (Eggers and Park 2018; Garud et al. 2016) and how incumbents dealt with the ambiguity of trajectory shifts (Henfridsson and Yoo 2013; Munir and Phillips 2005). Exaptation refers to the interpretation (sensemaking) and usage of technologies in a different way than what was initially intended (Garud et al. 2016). The results reveal that native MSPs used contemporary technologies as a bricoleur to foster the exaptation of technologies. Furthermore, we show that incumbents first adopt each technology separately according to their institutional logic (Munir and Phillips 2005). They then became aware of the new trajectory toward mass servitization by recognizing the increased demand. The more they learned during the process of sense-making of the innovation path the more uncertainties were identified. This is consistent with the work of Meacham (1983) who states that more knowledge in a new domain increases "the number of uncertainties, doubts, questions and uncertainties." Eventually, the incumbent tried to mitigate the uncertainty with the help of new technologies as demonstrated with the blockchain technology.

We note several limitations in the study's selected research approach. The embedded multiple-case study based on archival data does not provide us with the insights needed to conclude the motives of the native companies to come up with a platform as an architecture for servitization. We faced the challenge to re-build a technological trajectory using archival data within three different timespans without performing any intervention through interviews. Archival data offers the advantage of just describing the current situation, avoiding the trap of hindsight bias and backward sense-making of interviewees (Fischhoff and Beyth 1975). However, this approach limits the explanatory power when answering why and how the native companies developed a platform. We propose that future research elaborates with the founders of native platforms on the adoption process of technological trajectories to establish a more in-depth understanding of the motives and process of combining several technologies. Next, we restricted the single-case study to one incumbent that is currently transforming toward an MSP. The research community would benefit from a longitudinal study on how the incumbent managed the transformation and shift between trajectories to contribute toward a more detailed understanding of how companies transition from the old trajectory through a state of liminality to the new trajectory of mass servitization. Furthermore, interviews with additional incumbents would increase the robustness of the findings.

\section{Conclusion}

As platform research focuses mainly on established MSPs (de Reuver et al. 2017; McIntyre and Srinivasan 2017), it is not yet understood how technology enabled MSPs to emerge. We use the theoretical lens of technological trajectories (Dosi 1982; Kline and Rosenberg 2010) and technology diffusion (Rogers 2003; Zhu et al. 2006) to contribute toward an increased understanding of the emergence of MSPs. Out of this literature, we derive four propositions that describe the emergence of platforms through risk-taking actors that exploit a new technological trajectory and the diffusion and internalization of incumbents. We validate the four propositions through an embedded multiple-case study subject to the three native mobility service platforms Uber, BlaBlaCar and Flixbus, and an incumbent in the field of mobility services that was transforming toward an MSP provider. The results show that native platforms do not assimilate to distinct technologies, but rather adhere to the principle of bricolage, i.e., assembling a variety of technologies ranging from Web 2.0 functionality, mobile devices, cloud computing and big data analytics. Those technologies aim to support the provision of mobility services, leading to an architecture of servitization. During the routinization of those technologies, native platforms came up with a microservice architecture. As proposed by the theory, the new technology indeed fostered the creation of new demand in the form of the gig or sharing economy. The combination of contemporary technologies and the created demand gave rise to an innovation path toward mass servitization, which in turn triggered the transformation of the incumbents to transform toward an MSP provider. Overall, our research shows that native platforms routinize an architecture of servitization (MSPs) to create and satisfy the increasing demand for convenient services. This interplay of technology push and demand pull factors shows the emergence of MSPs as a new technological trajectory toward mass servitization. Moreover, MSPs are likely to gain more traction through emerging technologies such as artificial intelligence, which further increases the degree of automation and blockchain technology that enhances the trust and transparency over data in an ecosystem of different actors.

Acknowledgements The authors would like to thank all anonymous reviewers and the editors for their helpful comments and suggestions. This work is part of the TUM Living Lab Connected Mobility (TUM LLCM) project and has been funded by the Bavarian Ministry of Economic Affairs, Energy and Technology (StMWi) through the Center Digitisation.Bavaria, an initiative of the Bavarian State Government.

Open Access This article is distributed under the terms of the Creative Commons Attribution 4.0 International License (http:// creativecommons.org/licenses/by/4.0/), which permits unrestricted use, distribution, and reproduction in any medium, provided you give appropriate credit to the original author(s) and the source, provide a link to the Creative Commons license, and indicate if changes were made. 


\section{References}

Alt, R., \& Klein, S. (2011). Twenty years of electronic markets research looking backwards towards the future. Electronic Markets, 21(1), $41-51$.

Alt, R., Abramowicz, W., \& Demirkan, H. (2010). Service-orientation in electronic markets. Electronic Markets, 20(3-4), 177-180.

Antich, M. (2007). Analyzing Depreciation Trends: 2007 Vs. 2006. https:/www.automotive-fleet.com/blog/market-trends/story/2007/ 11/analyzing-depreciation-trends-2007-vs-2006.aspx. Accessed 01. 02.2018 .

Baker, T., \& Nelson, R. E. (2005). Creating something from nothing: Resource construction through entrepreneurial bricolage. Administrative Science Quarterly, 50(3), 329-366.

Benlian, A., Hilkert, D., \& Hess, T. (2015). How open is this platform? The meaning and measurement of platform openness from the Complementors' perspective. Journal of Information Technology, 30(3), 209-228.

Berger, T., Chen, C., \& Frey, C. B. (2018). Drivers of disruption? Estimating the Uber effect. European Economic Review, 110, 197210.

Bharadwaj, A., El Sawy, O. A., Pavlou, P. A., \& Venkatraman, N. (2013). Digital business strategy: Toward a next generation of insights. MIS Quarterly, 37(2), 471-482.

BlaBlaCar (2018). Fail. Lern. Succeed. https:/www.blablacar.com/blog/ inside-story/fail-learn-succeed Accessed 01.02.2018.

Boudreau, K. (2010). Open platform strategies and innovation: Granting access vs. devolving control. Management Science, 56(10), 18491872.

Bouwman, H., Haaker, T., \& De Vos, H. (2007). Mobile service bundles: The example of navigation services. Electronic Markets, 17(1), 20 28.

Burgelman, R. A., Maidique, M. A., \& Wheelwright, S. C. (2008). Strategic Management of Technology and Innovation (Vol. 5). Irwin Chicago, IL: McGraw-Hill Education.

Butcher, D. (2005). Top Technology Trends of 2005. https://news. thomasnet.com/imt/2005/12/06/2005 top techno. Accessed 01.09. 2018.

Cannon, S., \& Summers, L. H. (2014). How Uber and the sharing economy can win over regulators. Harvard Business Review, 13(10), 24 28.

Casprini, E., Paraboschi, A., \& Diminin, A. (2015). Web 2.0 Enabled Business Models: An Empirical Investigation on the Blablacar. It Case. In Proceedings of the Academy of Management Annual Meeting, Briarcliff Manor, NY, 2015.

Chen, M. K., \& Sheldon, M., (2016). Dynamic pricing in a labor market: Surge pricing and flexible work on the Uber platform. In Proceedings of the 2016 ACM conference on economics and computation, Maastricht, Netherlands, 2016.

Christensen, C. (2016). The Innovator's dilemma: When new technologies cause great firms to fail. Boston, MA: Harvard Business Review Press.

Ciborra, C. U. (2009). Technology, Work and Globalization. In C. Avgerou, G. Lanzara, \& L. Willcocks (Eds.), Bricolage, Care and Information Systems (pp. 206-220). Basingstoke, UK: Palgrave Macmillan UK.

Costantini, V., Crespi, F., Martini, C., \& Pennacchio, L. (2015). Demandpull and technology-push public support for eco-innovation: The case of the biofuels sector. Research Policy, 44(3), 577-595.

Dosi, G. (1982). Technological paradigms and technological trajectories. A suggested interpretation of the determinants and directions of technical change. Research Policy, 11(3), 147-162.

Drahokoupil, J., \& Fabo, B. (2016). The platform economy and the disruption of the employment relationship. ETUI Policy Briefs, 5(1).
Eggers, J., \& Park, K. F. (2018). Incumbent adaptation to technological change: The past, present, and future of research on heterogeneous incumbent response. Academy of Management Annals, 12(1), 357389.

Eisenhardt, K. M. (1989). Building theories from case study research. Academy of Management Review, 14(4), 532-550.

Fischhoff, B., \& Beyth, R. (1975). I knew it would happen: Remembered probabilities of once-Future things. Organizational Behavior and Human Performance, 13(1), 1-16.

Forbes (2013). 5 Surprising Marketing Trends for 2013. https://www. forbes.com/sites/thesba/2013/01/23/5-surprising-marketing-trendsfor-2013/. Accessed 01.02.2018.

Fortt, J. (2004). 2004's Top Technology Trends. https://www.forbes.com/ 2004/01/02/102techtrendspinnacor_ii.html\#144fc65511f5. Accessed 01.09.2018

Fraud, B. (2014). Micro-Services at Blablacar. http://blablatech.com/ blog/micro-service-at-blablacar. Accessed 01.02.2018.

Freeman, C. (2000). The Economics of Industrial Innovation (Vol. 3). London, UK: Routledge.

Gartner Inc. (2006). Gartner's 2006 emerging technologies hype cycle highlights key technology themes. Gartner Inc.

Gartner Inc. (2008). Gartner highlights 27 technologies in the 2008 hype cycle for emerging technologies. Gartner Inc.

Gartner Inc. (2009). Gartner's 2009 hype cycle special report evaluates maturity of 1,650 technologies. Gartner Inc.

Gartner Inc. (2012). Gartner's 2012 hype cycle for emerging technologies identifies "tipping point" technologies that will unlock long-awaited technology scenarios. Gartner Inc.

Gartner Inc. (2013). Gartner's 2013 hype cycle for emerging technologies maps out evolving relationship between humans and machines. Gartner Inc.

Garud, R., \& Karnøe, P. (2003). Bricolage versus breakthrough: Distributed and embedded Agency in Technology Entrepreneurship. Research Policy, 32(2), 277-300.

Garud, R., Jain, S., \& Kumaraswamy, A. (2002). Institutional entrepreneurship in the sponsorship of common technological standards: The case of sun Microsystems and Java. Academy of Management Journal, 45(1), 196-214.

Garud, R., Gehman, J., \& Giuliani, A. P. (2016). Technological exaptation: A narrative approach. Industrial and Corporate Change, 25(1), 149-166.

Ghazawneh, A., \& Henfridsson, O. (2013). Balancing platform control and external contribution in third-party development: The boundary resources model. Information Systems Journal, 23(2), 173-192.

Green, K., McMeekin, A., \& Irwin, A. (1994). Technological trajectories and R\&D for environmental innovation in Uk firms. Futures, 26(10), 1047-1059.

Gremm, C. (2017). Impacts of the German interurban bus market deregulation on regional railway services. In In Proceedings of the International Conference Series on Competition and Ownership in Land Passenger Transport, Stockholm, Sweden.

Grimaldi, R., Augustin, K., \& Beria, P. (2017). Intercity coach liberalisation. The cases of Germany and Italy. Transportation Research Procedia, 25, 474-490.

Haddad, E. (2015). Service-oriented architecture: Scaling the Uber engineering codebase as we grow. https://eng.uber.com/soa/. Accessed 01.11.2017.

Hagiu, A., \& Wright, J. (2015). Multi-sided platforms. International Journal of Industrial Organization, 43, 162-174.

Hein, A., Schreieck, M., Wiesche, M., \& Krcmar, H. (2016). MultipleCase Analysis on Governance Mechanisms of Multi-Sided Platforms. In Proceedings of the Multikonferenz Wirtschaftsinformatik, Ilmenau, Germany.

Hein, A., Böhm, M., \& Krcmar, H. (2018a). Tight and Loose Coupling in Evolving Platform Ecosystems: The Cases of Airbnb and Uber. In Abramowicz W., \& P. A. (Eds.), Business Information Systems. Bis 
2018. Lecture Notes in Business Information Processing (Vol. 320, pp. 295-306). Berlin, Germany: Springer, Cham.

Hein, A., Scheiber, M., Böhm, M., Weking, J., \& Krcmar, H. (2018b). Towards a Design Framework for Service Platform Ecosystems. In Proceedings of the 26th European Conference on Information Systems, Portsmouth, UK.

Hein, A., Weking, J., Schreieck, M., Wiesche, M., Böhm, M., \& Krcmar, H. (2019). Value co-creation practices in business-to-business platform ecosystems. Electronic Markets, 1-16. https://doi.org/10. 1007/s12525-019-00337-y .

Henfridsson, O., \& Yoo, Y. (2013). The liminality of trajectory shifts in institutional entrepreneurship. Organization Science, 25(3), 932950.

Herrmann, W. (2016). Flixbus-Cio Krauss: Der Usp Liegt in Den Algorithmen. https://www.computerwoche.de/a/flixbus-ciokrauss-der-usp-liegt-in-den-algorithmen. Accessed 01.02.2018.

Hicks, J. (1963). The Theory of Wages (Vol. 2). London, UK: Macmillan / St. Martin's Press.

von Hippel, E. (1976). The dominant role of users in the scientific instrument innovation process. Research Policy, 5(3), 212-239.

Hounshell, D. (1985). From the American System to Mass Production, 1800-1932: The Development of Manufacturing Technology in the United States (Vol. 4). Baltimore, MD: Johns Hopkins University Press.

IEEE Connected Vehicles (2016). Toyota Establishes a Mobility Services Platform and Announces Collaboration with a Car-Sharing Company. http://sites.ieee.org/connected-vehicles/2016/10/31/ toyota-establishes-mobility-services-platform-announcescollaboration-car-sharing-company/. Accessed 01.03.2018.

Isenson, R. (1968). Technology in Retrospect and Critical Events in science (project Traces). Illinois Institute of Technology/National Science Foundation. Chicago.

Jaffe, A. B., \& Stavins, R. N. (1995). Dynamic incentives of environmental regulations: The effects of alternative policy instruments on technology diffusion. Journal of Environmental Economics and Management, 29(3), 43-63.

Karhu, K., Gustafsson, R., \& Lyytinen, K. (2018). Exploiting and defending open digital platforms with boundary resources: Android's five platform forks. Information Systems Research, 29(2), 479-497.

Kasman, A., \& Duman, Y. S. (2015). Co2 emissions, economic growth, energy consumption, trade and urbanization in new Eu member and candidate countries: A panel data analysis. Economic Modelling, 44, 97-103.

Katz, M. L., \& Shapiro, C. (1994). Systems competition and network effects. Journal of Economic Perspectives, 8(2), 93-115.

Kenney, M., \& Zysman, J. (2016). The rise of the platform economy. Issues in Science and Technology, 32(3), 61-69.

Kim, D.-J., \& Kogut, B. (1996). Technological platforms and diversification. Organization Science, 7(3), 283-301.

Klein, H. K., \& Myers, M. D. (1999). A set of principles for conducting and evaluating interpretive field studies in information systems. MIS Quarterly, 23(1), 67-94.

Kleinknecht, A., \& Verspagen, B. (1990). Demand and innovation: Schmookler re-examined. Research Policy, 19(4), 387-394.

Kline, S. J., \& Rosenberg, N. (2010). An overview of innovation. In N. Rosenberg (Ed.), Studies on Science and the Innovation Process: Selected Works of Nathan Rosenberg (pp. 173-203). Singapore. Singapore: World Scientific Publishing Co. Pte. Ltd.

Kooti, F., Grbovic, M., Aiello, L. M., Djuric, N., Radosavljevic, V., \& Lerman, K. (2017). Analyzing Uber's Ride-Sharing Economy. In Proceedings of the 26th International Conference on World Wide Web Companion, Perth, Australia, 2017 (pp. 574-582).

Kuhn, T. S. (1996). The Structure of Scientific Revolutions (Vol. 3). Chicago, IL: The University of Chicago Press.
Langley, A. (1999). Strategies for theorizing from process data. Academy of Management Review, 24(4), 691-710.

Lee, C.-P., \& Shim, J. P. (2007). An exploratory study of radio frequency identification (Rfid) adoption in the healthcare industry. European Journal of Information Systems, 16(6), 712-724.

Lévi-Strauss, C. (1966). The Savage Mind. Chicago, IL: University of Chicago Press.

Macmanus, R. (2006). 2006 Web Technology Trends. https://readwrite. com/2006/12/11/2006_web_technology_trends/. Accessed 01.02. 2018 .

Manyika, J., Chui, M., Brown, B., Bughin, J., Dobbs, R., Roxburgh, C., et al. (2011). Big data: The next frontier for innovation, competition, and productivity. https://www.mckinsey.com/business-functions/ digital-mckinsey/our-insights/big-data-the-next-frontier-forinnovation. Accessed 01.01.2018.

McIntyre, D. P., \& Srinivasan, A. (2017). Networks, platforms, and strategy: Emerging views and next steps. Strategic Management Journal, 38(1), 141-160.

Meacham, J. A. (1983). Wisdom and the Context of Knowledge: Knowing That One Doesn't Know. In D. Kuhn, \& A. John (Eds.), On the Development of Developmental Psychology (Vol. 8, pp. 111134). Basel, Switzerland: Karger Publishers.

Messerschmitt, D. G., \& Szyperski, C. (2005). Software Ecosystem: Understanding an Indispensable Technology and Industry (Vol. 1). Cambridge, MA: MIT Press Ltd.

Metcalfe, B. (2013). Metcalfe's law after 40 years of Ethernet. Computer, 46(12), 26-31.

Mowery, D., \& Rosenberg, N. (1979). The influence of market demand upon innovation: A critical review of some recent empirical studies. Research Policy, 8(2), 102-153.

Munir, K. A., \& Phillips, N. (2005). The birth of The'kodak Moment': Institutional entrepreneurship and the adoption of new technologies. Organization Studies, 26(11), 1665-1687.

Nappez, F., Blanc, N., \& Schwarz, N. (2015). Blablacar tech, behind the scene. http://previous.blablatech.com/blog/BlaBlaTech-behind-thescene. Accessed 01.02.2018.

Nelson, R. R., \& Winter, S. G. (1977). In search of useful theory of innovation. Research Policy, 6(1), 36-76.

Nemet, G. F. (2009). Demand-pull, technology-push, and governmentled incentives for non-incremental technical change. Research Policy, 38(5), 700-709.

O'Reilly, T. (2007). What is web 2.0: Design patterns and business models for the next generation of software. MPRA Paper, (7), 4578.

O'Reilly, C. A., III, \& Tushman, M. L. (2008). Ambidexterity as a dynamic capability: Resolving the Innovator's dilemma. Research in Organizational Behavior, 28, 185-206.

Patton, M. Q. (2014). Qualitative Research \& Evaluation Methods: Integrating theory and practice (Vol. 4). Thousand Oaks, CA: SAGE Publications Inc.

Pavitt, K. (1984). Sectoral patterns of technical change: Towards a taxonomy and a theory. Research Policy, 13(6), 343-373.

Pearson, A. W. (1990). Innovation strategy. Technovation, 10(3), 185192.

Perez, S. (2017). App Economy to Grow to $\$ 6.3$ Trillion in 2021, User Base to Nearly Double to 6.3 Billion. https://techcrunch.com/2017/ 06/27/app-economy-to-grow-to-6-3-trillion-in-2021-user-base-tonearly-double-to-6-3-billion/. Accessed 23.01.2018 2018.

Porter, M. E., \& Van der Linde, C. (1995). Toward a new conception of the environment-competitiveness relationship. Journal of Economic Perspectives, 9(4), 97-118.

Posselt, T., \& Roth, A. (2017). Microfoundations of organizational competence for Servitization. Journal of Competences, Strategy \& Management, 9, 85-107.

Raasch, C., Herstatt, C., \& Lock, P. (2008). The dynamics of user innovation: Drivers and impediments of innovation activities. International Journal of Innovation Management, 12(3), 377-398. 
Rajesh, R. (2016). Spring Microservices. Birmingham, UK: Packt Publishing Ltd.

Ranganathan, C., Seo, D., \& Babad, Y. (2006). Switching behavior of Mobile users: Do Users' relational investments and demographics matter? European Journal of Information Systems, 15(3), 269-276.

Reinhold, E. (2016). Rewriting Uber engineering: The opportunities microservices provide. https:/eng.uber.com/building-tincup/. Accessed 01.02.2018.

Rennings, K. (2000). Redefining innovation-Eco-innovation research and the contribution from ecological economics. Ecological Economics, 32(2), 319-332.

de Reuver, M., Sørensen, C., \& Basole, R. C. (2017). The digital platform: A research agenda. Journal of Information Technology, 33(2), $124-135$.

Rogers, E. M. (2003). Diffusion of innovations (Vol. 5). New York, NY: The Free Press.

Rose, I., \& Wheeler, M. (2017). How Blablacar created a global transport network. https://www.bbc.com/news/business-38597504. Accessed 01.02 .2018

Rosenberg, N. (1969). The direction of technological change: Inducement mechanisms and focusing devices. Economic Development and Cultural Change, 18(1, Part 1), 1-24.

Rosenberg, N. (1976). Perspectives on Technology. Cambridge, UK: Cambridge University Press.

Saad, C. (2016). Introducing Uber trip experiences. https://www.uber. com/newsroom/trip-experiences-api/. Accessed 01.02.2018.

Sanchez, R., \& Mahoney, J. T. (1996). Modularity, flexibility, and knowledge Management in Product and Organization Design. Strategic Management Journal, 17(S2), 63-76.

Schlesiger, C. (2016). Flixbus: Der Unheimliche Siegeszug Des StartUps. https://www.wiwo.de/unternehmen/dienstleister/flixbus-derunheimliche-siegeszug-des-start-ups/14680498.html. Accessed 01. 02.2018 .

Schmookler, J. (1966). Invention and Economic Growth. Cambridge, MA: Harvard University Press.

Schreieck, M., Hein, A., Wiesche, M., \& Krcmar, H. (2018). The Challenge of Governing Digital Platform Ecosystems. In C. Linnhoff-Popien, R. Schneider, \& M. Zaddach (Eds.), Digital Marketplaces Unleashed (pp. 527-538). Heidelberg, Germany: Springer.

Sherwin, C. W., \& Isenson, R. S. (1967). Project hindsight. Science, 156(3782), 1571-1577.

Singh, R., Mathiassen, L., \& Mishra, A. (2015). Organizational path constitution in technological innovation: Evidence from rural telehealth. MIS Quarterly, 39(3), 653-665.

Sirmon, D. G., Hitt, M. A., Ireland, R. D., \& Gilbert, B. A. (2011). Resource orchestration to create competitive advantage: Breadth, depth, and life cycle effects. Journal of Management, 37(5), 13901412.

Strauss, A., \& Corbin, J. M. (1990). Basics of Qualitative Research: Grounded Theory Procedures and Techniques (Vol. 2). Thousand Oaks, CA: SAGE Publications Inc.

Sutter, J. (2009). The top 10 tech trends of 2009. http://edition.cnn.com/ 2009/TECH/12/22/top.tech.trends.2009/index.html. Accessed 01. 02.2018 .

Thornton, P. H., \& Ocasio, W. (2008). Institutional Logics. In R. Greenwood, C. Oliver, \& T. Lawrence (Eds.), The Sage Handbook of Organizational Institutionalism (pp. 99-128). London, UK: Sage Publications Ltd.

Tiwana, A., Konsynski, B., \& Bush, A. A. (2010). Platform evolution: Coevolution of platform architecture, governance, and environmental dynamics. Information Systems Research, 21(4), 675-687.

Ulanoff, L. (2012). 11 Big Tech Trends You'll See in 2013. https:// mashable.com/2012/12/06/tech-trends-2013. Accessed 01.02.2018.

Vandermerwe, S., \& Rada, J. (1988). Servitization of business: Adding value by adding services. European Management Journal, 6(4), 314-324.

Vernon, R. (1966). International investment and international trade in the product cycle. The Quarterly Journal of Economics, 80(2), 190 207.

Weick, K. E., Sutcliffe, K. M., \& Obstfeld, D. (2005). Organizing and the process of Sensemaking. Organization Science, 16(4), 409-421.

Willing, C., Brandt, T., \& Neumann, D. (2017). Electronic mobility market platforms-a review of the current state and applications of business analytics. Electronic Markets, 27(3), 267-282.

Wright, A. L., \& Zammuto, R. F. (2013). Wielding the willow: Processes of institutional change in English County cricket. Academy of Management Journal, 56(1), 308-330.

Yin, R. K. (2017). Case Study Research and Applications: Design and Methods (Vol. 6). Thousand Oaks, CA: Sage Publications.

Yoo, Y., Boland, R. J., Lyytinen, K., \& Majchrzak, A. (2012). Organizing for innovation in the digitized world. Organization Science, 23(5), $1398-1408$.

Zhu, K., Kraemer, K. L., \& Xu, S. (2006). The process of innovation assimilation by firms in different countries: A technology diffusion perspective on E-business. Management Science, 52(10), 15571576.

Publisher's note Springer Nature remains neutral with regard to jurisdictional claims in published maps and institutional affiliations. 